\title{
Impact of Body Perception and Self-Esteem Status in Patients with Fournier's Gangrene
}

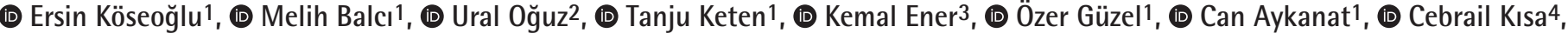 \\ (D) Bülent Erol5, (D) Altuğ Tuncel ${ }^{1}$ \\ 1 University of Health Sciences Turkiye, Ankara Numune Training and Research Hospital, Clinic of Urology, Ankara, Turkiye \\ ${ }^{2}$ Giresun University Faculty of Medicine, Department of Urology, Giresun, Turkiye \\ 3 University of Health Sciences Turkiye, Ankara Atatürk Training and Research Hospital, Clinic of Urology, Ankara, Turkiye \\ ${ }^{4}$ University of Health Sciences Turkiye, Ankara Dışkapı Training and Research Hospital, Clinic of Psychiatry, Ankara, Turkiye \\ 5Medeniyet University Faculty of Medicine, Department of Urology, Istanbul, Turkiye
}

\section{What's known on the subject? and What does the study add?}

No studies in literature have been reported about evaluating the psychological status of patients with Fournier's gangrene (FG). We evaluated the body perception and self-esteem status of patients, and determined that patients with FG have the tendency for low illness perception and high depression mood status.

\section{Abstract}

Objective: This study aimed to determine the body perception and self-esteem status of patients with Fournier's gangrene (FG) using the Body Cathexis scale (BCS) and Rosenberg's Depressed Mood subscale (RSES). Validity of the FG Severity index (FGSI), designed to determine disease severity in these patients, has also been evaluated.

Materials and Methods: A total of 44 men who underwent surgery for FG in authors' clinics between December 2009 and December 2018 were included in this study. Body perception and self-esteem status of patients with FG were measured by BCS and RSES in our study. The FGSI was evaluated and stratified by survival.

Results: The mean age of patients was $60 \pm 12$ (range: $35-77)$ years. Out of 44 patients; $18.1 \%(n=8)$ died, whereas $81.9 \%$ ( $n=36)$ survived. The average BCS score of patients was $89 \pm 33$ (range: 43-159). The mean BCS score of non-survivors was lower than that of survivors (59 \pm 25 and $94 \pm 31$, respectively) ( $p=0.002$ ). The average RSES score of patients was $2 \pm 1$ (range: $0-5$ ). No statistically significant difference noted between RSES scores of non-survivors and survivors ( $3 \pm 1$ vs $2 \pm 1)(p=0.1)$. FGSI scores of non-survivor and survivor groups were similar $(p=0.15)$.

Conclusion: Patients with FG have the tendency for low illness perception and high depression mood status. Also, FGSI score could not predict the disease severity and patients' survival. Follow-up of psychological status of these patients might yield higher treatment success and lower mortality rates.

Keywords: Fournier's gangrene, Rosenberg's Depressed Mood subscale, Body Cathexis scale

\section{Introduction}

Fournier's gangrene (FG), a life-threatening necrotising fasciitis of the genitourinary tract, which was first described by a French dermatologist Jean-Alfred Fournier in 1883 (1). Fournier reported the disease to be a pathology localised to the scrotum and penis, but FG is now known to have a potential to extend rapidly through the perineum, perianal tissues and even the anterior abdominal wall $(1,2)$. The improving knowledge provided an algorithm through the aetiology and diagnosis to optimal medical and surgical treatment; however, mortality rates of FG still range between 10\%-50\% (3-6). The high mortality rate of FG has led to focus studies mainly on prognosis of the disease. However, none of studies in literature have aimed to release

Correspondence: Melih Balcı MD, University of Health Sciences Turkiye, Ankara Numune Training and Research Hospital, Clinic of Urology, Ankara, Turkiye Phone: +90 5303916150 E-mail: drmelb@hotmail.com ORCID-ID: orcid.org/0000-0002-1506-941X

Received: 11.04 .2020 Accepted: 10.07.2020

Cite this article as: Köseoğlu E, Balcı M, Oğuz U, Keten T, Ener K, Güzel Ö, Aykanat C, Kısa C, Erol B, Tuncel A. Impact of Body Perception and Self-Esteem Status in Patients with Fournier's Gangrene. J Urol Surg 2021;8(1):13-17.

${ }^{\circ}$ Copyright 2020 by the Association of Urological Surgery / Journal of Urological Surgery published by Galenos Publishing House. 
the psychological status of patients with FG. According to our observation, patients with FG are late in clinic admission, with perceptions problems about the disease.

This study aimed to determine the body perception and selfesteem status of patients with FG using the Body Cathexis scale (BCS) and Rosenberg's Depressed Mood subscale (RSES). The validity of the FG Severity index (FGSI), which was designed to determine disease severity in these patients, was also evaluated.

\section{Materials and Methods}

After the ethical committee approval (ANEAH: 2008-0044), a total of 44 men who underwent surgery for FG in authors' clinics between December 2009 and December 2018 were included in this study. All participants provided informed consent. The data enclosing medical history as well as biochemical and haematological laboratory study results were recorded upon admission. The timing and extent of surgical debridement were also indicated.

FG extension was calculated using nomogram, assessing the extent of burn injuries with the following: penis, scrotum and perineum 1\% surface area each and each ischiorectal fossa is 2.5\% (7). Preoperatively, all patients were administered with intravenous hydration and empirical antibiotherapy including 4 $\mathrm{g} /$ day of ceftriaxone and $1.5 \mathrm{~g} /$ day of metronidazole.

All patients underwent immediate debridement comprising resection of all necrotic skin, subcutaneous tissue, fascia and muscle until the viable tissue was revealed. Culture samples from necrotic tissues and abscess content were taken during debridement to determine the proper postoperative antibiotherapy. After the initial debridement, clean margined wounds of hemodynamically stable patients were debrided twice a day under local anaesthesia at the bedside. In case of a need for a broader debridement, patients were returned to the operation room after 24-48 hours from the first operation. Reconstruction and wound closure approaches (split thicknessskin grafting, rotational flaps and negative pressure wound therapy) were performed after obtaining the viable tissue beneath the granulation.

FGSI is a numerical scoring system utilised to determine the risk of mortality of patients with FG. FGSI consisted clinical (temperature, heart and respiratory rate) and laboratory (serum sodium, potassium, bicarbonate, creatinine level, haematocrit and leukocytic count) parameters. The degree of deviation from normal is graded from 0 to 4 for all parameters. FGSI score is obtained by the sum of all values (7). In this study, body perception and self to esteem status of patients with FG were measured by BCS and RSES. These forms were given to patients on the second postoperative day. BCS here is used to establish the association between the total score of the Dresden Body Image Questionnaire with body satisfaction, which was originally developed by Secord and Jourard (8) to assess the degree of satisfaction with parts and processes of the body. The original scale has 46 items, but most recent studies utilise a 40 to item version. Subjects evaluate body characteristics according to a 5 to point Likert scale, ranging from strongly negative to strongly positive, with higher scores reflecting greater body satisfaction. Orlandi et al. (9) stated that BCS is a useful instrument to address satisfaction with the body and judge the emphasis on bodily functions next to body parts to be an advantage. No cut off value is used. An overall score is achieved by summing the items. The highest total score is 200 . RSES includes overall 63 items, with 12 sub to scales exploring aspects of self to esteem including self to confidence and self to liking. It contains positively worded items (e.g. "I feel that I have a number of good qualities") and negatively worded items Subscale of depression which includes 6 items. The highest total score is 6 . A score between 0 and 2 is accepted as normal, with higher scores indicating a higher level of self-esteem. The depressive mood increases as the score gets higher (10). BCS and RSES were applied by one of the psychiatrist (C.K.).

\section{Statistical Analysis}

Statistical Package for Social Sciences for Windows (SPSS, Chicago, USA) version 13.0 was used for statistical analysis. Descriptive statistics were obtained as mean \pm standard deviation. Data with normal distribution were compared with Student t-test, and data with abnormal distribution were compared with Mann-Whitney U test. Pearson correlation analysis was performed for the correlations. $\mathrm{P}<0.05$ was considered statistically significant.

\section{Results}

The mean age of patients was $60 \pm 12$ (range: $35-77$ ) years. Out of 44 patients, 18.1\% $(n=8)$ died, whereas $81.9 \%(n=36)$ survived. Non-survivors were older than survivors $\left(69_{ \pm} 7\right.$ vs $58 \pm 11)(p=0.01)$.

Predisposing factors of patients were investigated. A total of 27 (61.3\%) patients had uncontrolled diabetes mellitus (DM) (4 non-survivors and 23 survivors). Atherosclerotic coronary heart diseases were found in 10 patients (22\%) (3 non-survivors and 7 survivors). Chronic renal failure was present in three patients $(6.8 \%)$ ( 1 non-survivor and 2 survivors). Two patients (4.5\%) (2 survivors) had anorectal fistula. Three patients (6.8\%) (1 nonsurvivor and 2 survivors) had histories of hemorrhoidectomy operations. None of all patients had prior endourological interventions or indwelling urethral catheters upon admission. 
The mean extent of the body surface area involved in the necrotising process (BSAl) was $2.3 \% \quad \pm 2$. No statistically significant difference was noted between the mean BSAl of non-survivors and survivors $(1 \% \pm 0.4$ vs $2.5 \% \pm 2)(p=0.06)$.

The mean admission FGSI score was $3 \pm 3$ (range: 0-13). The FGSI scores of non-survivor and survivor groups were similar $(p=0.15)$.

The average BCS score of patients was $89 \pm 33$ (range: 43-159). The mean BCS score of non-survivors was lower than survivors $(59 \pm 25$ and $94 \pm 31$, respectively, with $p=0.002$ ). The average RSES score of patients was $2 \pm 1$ (range: $0-5$ ). No statistically significant difference was noted between RSES scores of nonsurvivors and survi-vors ( $3 \pm 1$ vs $2 \pm 1, p=0.1)$. No influence of age on the BCS and RSES scores ( $p>0.05)$ was noted.

In the correlation analysis, no correlations were found between BCS and RSES scores of patients (RBCS-RSES $=-0.15$ ). BSAI correlations of BCS and RSES scores were significant (pBCS$B S A I=0.02$ vs pRSES- BSAI $=0.01$ ). BCS scores of patients had a negative correlation with FGSI scores (RBCS-FGSI $=-0.8$ ). However, no correlation between RSES and FGSI scores was found (RRSES-FGSI $=-0.01$ respectively).

\section{Discussion}

FG is a rapidly progressing necrotising fasciitis of the scrotum, penis, perineum and perianal regions. This rapid progress is a result of endarteritis obliterans due to microorganism invasion into the subcutaneous tissue with local oedema, hypoxia and decreased local blood supply. The reduced oxygen in tissues extinguishes bacterial proliferation, necrosis and digestion of fascial layers (2-4). DM, chronic renal failure, urethral stricture, genitourinary infections, anorectal infections, trauma and malignancies were reported as etiological factors of $F G$ in several studies (5-7). In light of literature, DM is a major predisposing factor with an incidence rate of 46-76.9\% $(2,3)$. In accordance to literature, $61.3 \%$ of patients had uncontrolled DM in our study. Out of 8 patients who died, 1 had two illnesses and 6 had one illness. Additionally, $61.1 \%$ of survivors and $50 \%$ of nonsurvivors had DM. Hence, DM is the most common predisposing factor in our study.

Historically, FG was described as a disease of youth (1). Recently, the mean age of patients with FG has increased rapidly (3). In our study, the mean age of patients was 60.4 years. The effect of age on survival is controversial according to literature. Some authors reported no significant difference between ages of survivors and non-survivors. However, a large group of studies reported non-survivors' poor prognosis to be significantly associated with their older ages (11). In our study, non-survivors were significantly older than the survivors.
The effect of the extent of the necrotising tissue was investigated in various studies. We previously reported BSAl as one the most prognostic factor in patients with FG (6). Antipathetically, our study showed that BSAI have no negative effect on the outcome in patients (4). In contrast to our previous studies, BSAI had no predictive contribution on mortality of patients in the current study.

Improving knowledge about the aetiology, predisposing factors, diagnosis, treatment options and intensive care techniques have provided awareness for $\mathrm{FG}$; however, mortality rates are still high (2-6). The mortality rate was $18.1 \%$ in our study. High mortality rates have promoted investigations on stratifying risks of mortality in patients with FG. FGSI was described by Laor to predict the prognosis, severity and mortality of the disease (7). Laor et al. (7) also determined 9 as a cutoff value. Patients with FGSI scores above 9 were expected to have more severe and fatal clinical outcomes. However, Tuncel et al. (5), reported the median admission FGSI scores were 2.5 and 5 for survivors and non-survivors, respectively, but the difference was not significant, and they found no relation between FGSI and mortality. In our study, we found no significant correlation between FGSI and mortality either.

Majority of studies in literature have been focused on comparisons of results of surviving and non-surviving patients with FG due to the fatality of the disease. However, psychological status of patients with FG has never been a centre of interest in literature before. Medical and psychological literatures use Leventhal's Common-Sense Model for the evaluation and treatment of patients (12). In this model, cognitions based on past experiences and interpretations of symptoms are all referred to as illness perception $(12,13)$. Illness perception is known to increase patient's self-control in diseases (14). Illness perception has been analysed in several organ pathologies such as cardiovascular disorders (15), respiratory disorders (16) and musculoskeletal disorders e.g. fibromyalgia (17), sports injuries (18), Chronic Fatigue syndrome and rheumatoid arthritis (13). The level of negative reactions and feelings related to the disease and treatment decreases as the level of illness perception increases (19). Richters et al. (20) investigated the effect of positive surgical margins (PSM) on illness perception after radical prostatectomy in patients with prostate cancer. In their study, patients with PSM were reported to have a higher illness perception rates than patients with negative surgical margins which yield an increase in treatment benefit. BCS is a stable and consistent method for evaluating body and illness perception $(9,21)$. Body cathexis is the impact of bodily features on the individual's psychological status (22). BCS was first developed by Secord and Jourard (8) in 1953. BCS was designed to assess the degree of satisfaction or dissatisfaction felt about sundry parts and processes of the body. Cam and Gumus. (23) reported 
patients with higher body perception scores in BCS give more importance to their health. In our study, patients with FG had a mean BCS score of 88.8 which stands for a low body and illness perception. Non-survivors had a significantly higher BCS scores than the survivors. This data was interpreted as a lower understanding of FG to lead an unawareness of the developing highly aggressive necrotising disease. This lack of awareness also makes the treatment process challenging.

Body perception is one of the most determinative characteristics of self-esteem which represents the individual's self-confidence. Self-esteem provides an individual to maintain a healthy life and take care of himself and concern with his health as a result (23). In this study, patients with FG had a mean RSES score of 2.4 which repre-sents a tendency towards depression and decreased self-esteem. Stein reported depression's negative alterations on immune system in 1989 (24). Depression and increased depressed mood would be considered to have unfavourable effects on the developmental process of the disease when majority of predisposing factors of FG are thought to be related with decreased immunoreactivity (2). In several studies depression was revealed as an etiological factor in various chronic diseases such as inflammatory bowel disease and ulcerative colitis (25-28). Low self-esteem was also shown to have a diminished adherence to treatment (29).

To our knowledge, this is the first study that evaluates the illness, body perception and self-esteem status of patients with FG in literature. Our results pointed out that low body perception and self-esteem status might result to a late notice of their own illness and postpone their admission to a doctor. Our data should be supported by other prospective studies.

\section{Conclusion}

Our results show that patients with FG have the tendency for low illness perception and high depression mood status. Also, FGSI score could not predict the disease severity and patients' survival. We believe that close follow-up of psychological status of these patients might yield higher treatment success and lower mortality rates. These results need to be confirmed with further studies.

\section{Ethics}

Ethics Committee Approval: The study was approved by Ankara Numune Training and Research Hospital Ethics Committee (approval number: ANEAH: 2008-0044).

Informed Consent: All participants provided informed consent. Peer-review: Externally and internally peer-reviewed.

\section{Authorship Contributions}

Supervision: A.T., Concept: M.B., Design: M.B., Data Collection or Processing: U.O., T.K., K.E., C.A., B.E., Analysis or Interpretation: E.K., M.B., C.K., Literature Search: Ö.G., Writing: E.K., M.B.

Conflict of Interest: No conflict of interest was declared by the authors.

Financial Disclosure: The authors declared that this study received no financial support.

\section{References}

1. Fournier JA. Gangrene foudroyante de la verge. Semin Med. 1883;3:345348.

2. Tarchouli $M$, Bounaim $A$, Essarghini $M$, Ratbi MB, Belhamidi MS, Bensal A, Zemmouri A, Ali AA, Sair K. Analysis of prognostic factors affecting mortality in Fournier's gangrene: A study of 72 cases. Can Urol Assoc J 2015;9:E800-804.

3. Tuncel A, Aydin 0, Tekdogan U, Nalcacioglu V, Capar Y, Atan A. Fournier's gangrene: Three years of experience with 20 patients and validity of the Fournier's Gangrene Severity Index Score. Eur Urol 2006;50:838-843.

4. Erol B, Tuncel A, Hanci V, Tokgoz H, Yildiz A, Akduman B, Kargi E, Mungan A. Fournier's gan-grene: overview of prognostic factors and definition of new prognostic parameter. Urology 2010;75:1193-1198.

5. Tuncel A, Keten $T$, Aslan $Y$, Kayali M, Erkan A, Koseoglu E, Atan A. Comparison of different scor-ing systems for outcome prediction in patients with Fournier's gangrene: experience with 50 patients. Scand J Urol 2014;48:393-399.

6. Erol B, Tuncel A, Tok A, Hanci V, Sari U, Sendogan F, Budak S, Aydemir H, Amasyali AS, Yild-irim A, Caskurlu T. Low magnesium levels an important new prognostic parameter can be overlooked in pa-tients with Fournier's gangrene: a multicentric study. Int Urol Nephrol 2015;47:1939-1945.

7. Laor E, Palmer LS, Tolia BM, Reid RE, Winter HI. Outcome prediction in patients with Fournier's gangrene. J Urol 1995;154:89-92.

8. Secord PF, Jourard SM. The appraisal of body-cathexis: body-cathexis and the self. J Consult Psychol 1953;17:343-347.

9. Orlandi E, Covezzi R, Galeazzi GM, Guaraldi GP. The Italian version of the Body Cathexis Scale. Eating Weight Disord 2006;11:e79-84.

10. Çuhadaroğlu F. Adolesanlarda Benlik Saygısı. Journal of Dependence. 2014;15:142-149.

11. Sorensen MD, Krieger JN, Rivara FP, Klein MB, Wessells $H$. Fournier's gangrene: Management and mortality predictors in a population based study. J Urol 2009;182:2742-2747.

12. Meyer $D$, Leventhal $H$, Gutmann M. Common-sense models of illness: the example of hypertension. Health Psychol 1985;4:115-135.

13. Leysen M, Nijs J, Meeus M, Paul van Wilgen C, Struyf F, Vermandel A, Kuppens $K$, Roussel NA. Clinimetric properties of illness perception questionnaire revised (IPQ-R) and brief illness perception question-naire (Brief IPQ) in patients with musculoskeletal disorders: A systematic review. Man Ther 2015;20:10-17.

14. Cybulski M, Cybulski L, Krajewska-Kulak E, Cwalina U. Illness acceptance, pain perception and ex-pectations for physicians of the elderly in Poland. BMC Geriatr 2017;8:17:46.

15. Schoormans D, Mulder BJ, van Melle JP, Pieper PG, van Dijk AP, Sieswerda GT, Hulsbergen-Zwarts MS, Plokker TH, Brunninkhuis LG, Vliegen HW Sprangers MA. IIIness perceptions of adults with congenital heart disease 
and their predictive value for quality of life two years later. Eur J Cardiovasc Nurs 2014;13:86-94.

16. Kaptein AA, Yamaoka K, Snoei L, Kobayashi K, Uchida Y, van der Kloot WA, Tabei T, Kleijn WC, Koster M, Wijnands G, Kaajan H, Tran T, Inoue K, van Klink $R$, van Dooren-Coppens E, Dik H, Hayashi F, Willems L, Annema-Schmidt D, Annema J, van der Maat B, van Kralingen K, Meirink C, Ogoshi K, Aaronson $\mathrm{N}$, Nortier $\mathrm{H}$, Rabe K. Illness perceptions and quality of life in Japanese and Dutch patients with non-small-cell lung cancer. Lung Cancer 2011;72:384390.

17. van Wilgen $C P$, van Ittersum $M W$, Kaptein $A A$, van Wijhe $M$. Illness perceptions in patients with fibromyalgia and their relationship to quality of life and catastrophizing. Arthritis Rheum 2008;58:3618-3626.

18. van Wilgen $\mathrm{CP}$, Keizer D. Neuropathic pain mechanisms in patients with chronic sports injuries: a diagnostic model useful in sports medicine? Pain Med 2011;12:110-117.

19. Niedzielski $A$, Humeniuk $E$, Blaziak $P$, Fedoruk D. The level of approval in selected chronic diseases. Wiad Lek 2007;60:5-6.

20. Richters A, Derks J, Husson O, van Onna IEW, Fossion LMCL, Kil PJM, Verhoeven RHA, Aarts MJ. Effect of surgical margin status after radical prostatectomy on health-related quality of life and illness perception in patients with prostate cancer. Urol Oncol 2015;33:16.e9-16.e15.

21. Secord PF, Jouard SM. The appraisal of body-cathexis: body-cathexis and the self. J Consult Psychol 1953;17:343-347.

22. Yagmur C, Ak S, Engin MS, Evin N, Kelahmetoglu O, Akbas H, Demir A. Columellar Scar Percep-tion in Open Rhinoplasty. Interplay of Scar
Awareness, Body Cathexis and Patient Satisfaction. Aesthetic Plast Surg 2017:41:153-160.

23. Cam O, Gumus AB. Breast cancer screening behavior in Turkish women: Relationships with health beliefs and self-esteem, body perception and hopelessness. Asian Pac J Cancer Prev 2009;10:49-56.

24. Stein M. Stress, depression, and the immune system. J Clin Psychiatry 1989;50:35-42.

25. Kurina LM, Goldacre MJ, Yeates D, Gill LE. Depression and anxiety in people with inflammatory bowel disease. J Epidemiol Community Health 2001;55:716-720.

26. Addolorato G, Capristo E, Stefanini GF, Gasbarrini G. Inflammatory bowel disease: a study of the association between anxiety and depression, physical morbidity, and nutritional status. Scand J Gastroenterol 1997;32:10131021.

27. Magni G, Bernasconi G, Mauro P, D'Odorico A, Sturniola GC, Canton G, Martin A. Psychiatric diagnoses in ulcerative colitis. A controlled study. $\mathrm{Br}$ J Psychiatry 1991;158:413-415.

28. Robertson DAF, Ray J, Diamond I, Edwards JG. Personality profile and affective state of patients with inflammatory bowel disease. Gut 1989;30:623-626.

29. Poorgholami F, Javadpour S, Saadatmand V, Jahromi MK. Effectiveness of Self-Care Education on the Enhancement of the Self-Esteem of Patients Undergoing Hemodialysis. Glob J Health Sci 2015;8:132-136. 